\title{
Study and Scrutiny: Research on Young Adult Literature
}

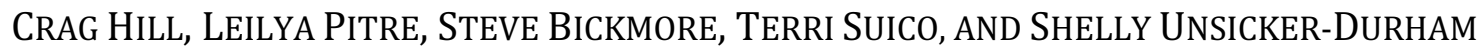

SPECIAL ISSUE

\section{Creative Contamination: Generating Enrichment Through Adaptation}

\section{INTRODUCTION}

Welcome to Study and Scrutiny: Research on Young Adult Literature, Volume 5/Issue 1. In this issue, the editors sought out critical and empirical articles for the theme, Creative Contamination: Generating Enrichment Through Adaptation. As we wrote in our Call for Manuscripts, authors "borrow from one another while they draw upon their own creativity to produce stories that are simultaneously unique and familiar. In Tree and Leaf, his essay On Fairy-Stories, J.R.R. Tolkien conceptualized a 'Cauldron of Story' that contains ingredients creators of story add to and draw from. He emphasizes that when we think of the Cauldron of Story, 'we must not wholly forget the Cooks. There are many things in the Cauldron, but the Cooks do not dip in the ladle quite blindly. Their selection is important.' Thus, no story is completely original, and authors deftly and purposefully select ingredients from the classic story when they create adaptations.

"Jack Zipes conceptualizes the process of adaptation as contamination, a term used by folklorists to describe foreign augmentation to what appears to be a pure narrative tradition. Although this has traditionally had a negative connotation, Zipes posits that it has generative aspects as well. 'Contamination can be an enrichment process; it can lead to the birth of something unique and genuine in its own right.' We see the process of contamination at work in adaptations."

We found it intriguing when we received a suite of empirical articles utilizing the Critical Comparative Content Analysis Method (CCCA). We were not conversant with this method, but the articles provided us with a solid education of it and an eagerness to see this method applied to adaptations of many kinds. One of the originators of the Critical Comparative Content Analysis, Mark Sulzer, agreed to give an overview of the method and three of the articles we accepted applying CCCA to young adult literature texts. 


\section{EMPIRICAL STUDIES WITH CRITICAL COMPARATIVE CONTENT}

\section{ANALYSIS METHOD by Mark Sulzer}

Imagine going into a bookstore to find a particular book. Maybe it's a book meant as a gift for a young person, maybe it's a book for yourself, or maybe it's for a class. Whatever the reason, imagine finding your book and going to the register to pay. Out of the corner of your eye, you see something that gives you pause. It's a display of new releases of a certain type: youth adaptations, fairy tale retellings, modernized classics, conventional novels reimagined through comics, movies based on books, and so on. A book at the center of the display looks like the one in your hand. Perhaps you've made a mistake. Perhaps the book you meant to buy is not the one in your hand, but the one in the display. You compare. They're the same. Sort of. The titles are comparable, very close. But the display book has a slightly different cover, and the date of publication is closer to present day. You double-check the titles. The newer book is definitely a version of the other. You flip through the pages. Your head moves back and forth, as if watching a tennis match. Same. Same. Same. That's different. And that's different. That's completely different. Same. Pretty much the same. Same. That's different. That's sort of the same. That's completely different....As you continue going back and forth, big questions raise in your mind: How exactly are these two pieces similar and different from each other? Who made the newer one and why? What's going on here?

This scenario was what originally initiated the development of Critical Comparative Content Analysis (CCCA), a methodology featuring a systematic comparison of two or more texts. I (Mark) was a doctoral candidate at the University of Iowa. Arriving at my advisor Amanda Thein's office for a meeting one day, I found Amanda and colleague Nita Schmidt poring over two books. They had been shopping at a bookstore in downtown Iowa City and picked up Wes Moore's memoir titled The Other Wes Moore, which explores how two young Black men growing up in Baltimore with the same name took divergent life paths. At the time, it was a book adopted as a common read at high schools and universities across the country. But they had also found another version of that book, sitting in a display, titled Discovering Wes Moore. The books sat side-by-side in Amanda's office, The Other Wes Moore (original) and Discovering Wes Moore (a youth adaptation). The covers had the exact same picture, presumably of a young Wes Moore, on a bike riding on a street in his hometown of Baltimore. But upon closer inspection, one could see the cover photos were mirrored: one showing the boy on the bicycle angled to the left and the other angled to the right. 
Our interest was piqued. We kept exploring. Over the next weeks and months, we systematically compared the two books, the purpose being to answer the big questions raised above, to explain what's going on here.

At the time, on Amanda and Nita's advice, I had recently read - consumed, been rivetted by - Lesko's (2012) Act Your Age!: A Cultural Construction of Adolescence, which traces the emergence of adolescence as a social category, connecting this emergence with discourses of youth in contemporary culture. Lesko's book offered a way to make sense of something we were seeing. We found that while the original version of the memoir approaches how institutional racism shaped Wes Moore's life and the life outcomes of youth of color, particularly of young Black men, the youth version doesn't. Instead, the youth adaptation aligns with the myth of meritocracy (Thein, Sulzer, \& Schmidt, 2013). In this youth adaptation of Wes Moore's memoir, we saw a clear, contemporary, material manifestation of Lesko's (2012) argument that youth are enfolded into the dominant myths that serve those in power. The YA publishing industry is a complex and layered one - e.g., hard to know is the degree to which the original author, Wes Moore, participated in the youth version of his own memoir or if it was completely ghostwritten - but in terms of textual representation, we saw that when youth were the imagined audience, the YA publishing industry was, in this case, oriented to serve dominant myths rather than disrupt them.

We presented this work in classes, workshops, and presentations. Skeptics would wonder if maybe the youth adaptations simply made the language on the page more accessible. No, we argued. Adjusting the language to make it more accessible is part of what's going on, sure, but that's not the whole story. We showed examples and designed activities focused on comparing textual representations, but it was clear that we needed a larger infrastructure of analysis, a methodology, to further this work. We formalized our methodology in "What is Adapted in Youth Adaptations? A Critical Comparative Analysis of Military Memoirs Repackaged as Young Adult Literature" (Sulzer, Thein, \& Schmidt, 2018), describing four stages of the analytic process:

a) a preparation stage involving initial readings of the texts and initial impressions from the research team recorded as analytic memos

b) a coding frame stage involving collecting points of comparison, often taking the form of a chart to document additions, omissions, revisions, and similar material

c) a coding stage involving the adoption and application of one or more coding styles (e.g., descriptive codes, versus codes, in vivo codes) to the coding frame

d) a final interpretation stage involving a recursive process of considering the codes, analytic memos, and examples from the texts 
These stages are not meant to be understood strictly linearly. Interpretations, for example, are always being produced, revised, and checked against examples from the texts from the first stage to the last.

Also foundational to CGCA is its attention to processes of production. CGCA assumes texts do not exist in a vacuum but are in dynamic relationship with authors, editors, ghost writers, readers, people buying on behalf of readers, contexts for reading, social and cultural norms, and more. Thus, as described in this issue, the comparative element in a CGCA "is geared toward calling forth and explaining patterns of difference between or among texts, maintaining the analytic stance that these textual differences emerge from, interact with, and participate in various discourses" (Sulzer et al., 2021, p. 29). The culminating interpretations of a CCCA therefore take on social, cultural, political, and historical dimensions (for additional examples, see Amato, 2019; Glenn \& Caasi, 2021; Sulzer, 2020, 2021; Thein, Sulzer, \& Schmidt, 2019).

Multiple traditions have influenced the development of CCGA: critical content analysis (Johnson et al., 2017), content analysis (Krippendorff, 2013), literary criticism (Trites, 2000), and critical discourse analysis (Rogers, 2011), allowing the methodology enough flexibility to address the manifold and idiosyncratic situations of comparison. Texts can be in relationship to each other in an infinite number of ways, and scholars bring with them their own talents and areas of specialization; thus, CCCA is a methodology that provides guidance but does not enumerate all possible methods. Methods within a CCCA should - and must - be invented to address particular projects and research questions. For example, for the piece in this issue (Sulzer et al., 2019), my colleagues and I found ourselves needing to invent methods using quantitative and qualitative data to address our research questions, particularly our interest in the structures of information across versions of the text (taking inspiration from Lynch, 2019).

As a methodology, CCCA resonates with the theme of this issue, Creative Contamination: Generating Enrichment through Adaptation. This theme highlights the idea that most (all?) texts owe their existence to a previous text, and proximity of one to the other is worth paying attention to so that teachers and scholars might pursue the most pertinent lines of inquiry in their work and/or with their students. CGCA is a methodology centered on such proximity, the idea being to systematically compare material between or among texts - contaminations, adaptations, revisions, re-imaginings, omissions, additions - in order to detail how the texts relate to each other and interpret that relationship through critical analysis. CCGA therefore also calls on various critical 
traditions to animate the analysis. In this issue, CCCAs take up Critical Race Theory, critical literacy, and critical youth studies, briefly described below.

In "Connecting and Critiquing the Canon: Pairing Pride and Pride and Prejudice," Banack (2021) details how characters, plot points, and themes in Pride and Prejudice by Jane Austen are reimagined in Pride by Ibi Zoboi. Banack's CGCA draws on Critical Race Theory to interpret how Zoboi's remixing of Austen's canonical text serves as a counterstory, centering Black lives and unpacking themes that hold scarce attention in Western canonical literature: whiteness as property, endemic racism, and cultural pride. Understanding the textures and nuances of how Pride draws on, remixes, and is in proximity to Pride and Prejudice can provide a basis for critical engagement in the classroom; Banak writes, "Pride can serve as a tool to launch critical discussions that ask our students to challenge their own thinking about race and racism, not only in Pride and Prejudice, but in society as a whole" (p. 20).

In 'Intensely Original: Disrupting the Horizon of Expectations of 'Beauty and the Beast' in A Curse so Dark and Lonely," Davis (2021) details how Brigid Kemmerer's contemporary retelling of Beauty and the Beast disrupts the reader's "horizon of expectations" about the story's thematic content, which both rejuvenates the identifies problems within the original fairy tale. Davis's CGCA draws on critical literacy and critical literature pedagogy to interpret how shifts in characterization, action vs. character development, and narratological features contribute to an affirming representation of disability and a critique of toxic masculinity. Layered through the analysis, Davis demonstrates how first-person narration provides opportunities for readers to find sympathetic and empathetic responses. Davis argues that contemporary retellings of fairy tales provide the context for critical literacy engagements in the classroom and "fantasy adaptations can act as tools for disrupting metanarratives" (p. 15).

In "Doctors, Drugs, and Danger: Disentangling Discourses of Adolescence/ts in Dreamland (original version) and Dreamland (young adult adaptation) with Critical Comparative Content Analysis," Sulzer, Colley, Hellmann, and Lynch (2021) detail how a youth adaptation of Dreamland, a nonfiction book about the opiate epidemic, (a) provides less information about the opiate epidemic, which is also delivered in a simpler structure; (b) keeps the reader at a greater rhetorical distance from people who might be deemed unsavory, and (c) gives a more optimistic view of the opiate epidemic in terms of progress achieved rather than action needed. Sulzer et al's CGCA draws on critical youth studies to interpret these changes in the text as a byproduct of discourses 
of adolescence/ts. Youth readers are positioned as needing simplicity, protection, and a sense of optimism. Sulzer et al. argue that youth adaptations provide opportunities for critical literacy in the classroom, as reading across these versions of the text would be a method of "invit[ing] student voices into a discussion about their own positioning as readers and thinkers in the world, and thus, a discussion about the relations of power, ideology, and narrative" (p. 31).

\section{A CRITICAL STUDY, INTERVIEWS, AND BOOK REVIEWS}

The story of Cinderella has endured through countless adaptations for over three centuries. In the critical study, "Cinderella's Transformation: Evolving from Patriarchal to $21^{\text {st }}$ Century Expressions of Femininity," Linda Parson analyzes the tropes of the patiently suffering heroine, the cruel stepmother, magical help, beauty as female currency, and being chosen by the prince in Cindrillon (Perrault, 1697), Mechanica (Cornwell, 2015), and Cinder (Meyer, 2012). The (re)visions deconstruct binary gender roles through heroines who liberate themselves from their servitude, prioritize independence over marriage, and experience supportive female relationships. The portrayals of the cruel stepmothers disrupt the trope of powerful women as inherently evil, and the storylines critique the injustices of Othering. These (re)visions reflect contemporary discourses that expand expressions of femininity.

This issue again includes an interview and book reviews. First, Terri Suico interviews Dana Lawrence and Amy Montz. The conversation centers on their 2020 book, Adaptation in Toung Adult Novels: Critically Engaging Past and Present. Included in the interview section is a new feature, Teacher Round Table, where a group of in-service teachers discuss one of the articles. This conversation includes Shaista Fenwick, Najah Amatullah Hylton, Suzanne Sutton, and Connor Woodard, all from the Oklahoma City Metro discussing Ariana Banack's "Connecting and Critiquing the Canon: Pairing Pride and Pride and Prejudice."

Extending the first interview, readers will find a second piece by Terri Suico, reviewing the book edited by Lawrence and Montz, including a description of the book's sections, a critical evaluation, and a set of recommendations. Finally, Suico has collected book reviews, sampling some of the forms adaptation can take in young adult literature, e.g. adapting time and place. These reviews written by Anita Dubroc, Ann Marie Smith, Lisa A. Hazlett, and Kathryn Caprino offer a critical examination of the stories and include ideas for classroom use. 


\section{References}

Amato, N. A. (2019). " I'm Fat. It's Not a Cuss Word.": A Critical Content Analysis of Young Adult Literature Featuring Fat Female Protagonists. Fournal of Language and Literacy Education, 15(1), n1.

Glenn, W.J., \& Caasi, E. (2021). Gendered assumptions in the framing of fitness in sports nonfiction for young adult readers. Children's Literature in Education. Advanced online publication. https://doi.org/10.1007/s10583-020-09432-7

Johnson, H., Mathis, J., \& Short, K. G. (Eds.). (2017). Critical content analysis of children's and young adult literature: Reframing perspective. New York, NY: Routledge.

Krippendorff, K. (2013). Content analysis: An introduction. Thousand Oaks, CA: SAGE.

Lesko, N. (2012). Act your age!: A cultural construction of adolescence. New York, NY: Routledge.

Lynch, T. L. (2019). Electrical evocations: Computer science, the teaching of literature, and the future of English education. English Education, 52(1), 15-37.

Rogers, R. (2011). An introduction to critical discourse analysis in education (2nd ed.). New York, NY: Routledge.

Sulzer, M. A. (2020). Border crossing from literature to young adult literature: A critical comparative content analysis of Enrique's Journey (original version) and Enrique's Journey (adapted for youth). The ALAN Review, 47(2), 12-24.

Sulzer, M. A. (2021). Two versions of Notorious RBG, two representations of Ruth Bader Ginsburg: How are they different and why does that matter? Annals of Social Studies Education Research for Teachers, 2(2), 26-33.

Sulzer, M. A., Thein, A. H., \& Schmidt, R. R. (2018). What is adapted in youth adaptations?: A critical comparative content analysis of military memoirs repackaged as young adult literature. Fournal of Language \& Literacy Education, 14(1), 1-27.

Thein, A. H., Sulzer, M. A., \& Schmidt, R. R. (2019). Gritical comparative content analysis: Examining race, politics, and violence in two versions of I am Malala. In Ginsberg, R., \& Glenn, W. (Eds.), Engaging critically with multicultural literature in the secondary classroom (pp. 153 161). New York, NY: Routledge.

Trites, R. S. (2000). Disturbing the universe: Power and repression in adolescent literature. Iowa City, IA: University of Iowa Press. 


\section{ACKNOWLEDGEMENTS}

This issue would not be possible without valuable input of our reviewers. We want to thank everyone who generously provided feedback and constructive, critical suggestions to the authors in order to strengthen and refine submissions. A special thank you goes to Julie Hoffman, Jennifer Dail, Abbey Backman, Joellen Maples, Angela Insenga, June Pulliam, Cindi Koudelka, Stacy Graber, April Bannon, Robert Prickett, Sharon Pajka, and Ruth Caillouet. It is your time and professional expertise that helped us in selecting articles for this issue.

As always, we invite teachers, librarians, graduate students, and educators who would like to review for us in the future. We invite reviewers who are passionate about YA literature and are able to share their knowledge and expertise to improve Study $\mathscr{E}^{2}$ Scrutiny as well as to spread the word about the journal. Please email Leilya Pitre (Leilya.Pitre@selu.edu), and we will gladly include your name and contact information in our database of reviewers.

Study E Scrutiny: Research on Young Adult Literature is an open access journal. As such it provides immediate access to its content on the principle that making research freely available to the public and supports a greater global exchange of knowledge. The University of Oklahoma is graciously hosting this journal and supporting it in many ways, including distribution. Thanks to Karen Rupp-Serrano, Nicholas Wojcik, and Jeannine Rainbolt College of Education Dean Stacy Reeder, for their continued support of this journal. 